\title{
Acute injury immediately post atrial fibrillation ablation defined by MRI
}

\author{
Christopher J McGann*, Eugene Kholmovski, Joshua Blauer, \\ Sathya Vijayakumar, Chris Gloschat, Edward DiBella, Gene Payne, \\ Gaston Vergara, Troy Badger, Rob MacLeod, Dennis Parker and \\ Nassir Marrouche
}

Address: University of Utah, Salt Lake City, UT, USA

* Corresponding author

from 13th Annual SCMR Scientific Sessions

Phoenix, AZ, USA. 21 -24 January 2010

Published: 21 January 2010

Journal of Cardiovascular Magnetic Resonance 20 I0, I2(Suppl I):MI doi:I0.I I86/I532-429X-I2-SI-MI

This abstract is available from: http://jcmr-online.com/content/I2/SI/MI

(C) 2010 McGann et al; licensee BioMed Central Ltd.

\begin{abstract}
Introduction
Catheter ablation is effective in symptomatic, drug refractory atrial fibrillation and can result in cure but success rates vary significantly with recurrences ranging from 40$86 \%$. In the months following ablation, LA wall scarring on late gadolinium enhancement (LGE) is useful for determining the location and extent of injury and has been used to guide follow up ablation to 'close the gaps' after unsuccessful PVAI. More recently, imaging acute ablation injury using double inversion recovery (DIR) sequences has been shown feasible and has generated interest for its potential clinical value in guiding ablations.
\end{abstract}

\section{Purpose}

To further define the tissue characteristics of acute injury to the LA wall immediately after ablation using a modified T2 weighted (T2w), DIR, turbo spin echo (TSE) sequence on a $3 \mathrm{~T}$ scanner.

\section{Methods}

Twenty-five patients presenting for AF ablation underwent underwent MR imaging pre- and immediately post ablation in an EP-MRI laboratory using a 3 Tesla MRI scanner (Verio, Siemens). Acute injury was imaged using a modified T2 $\mathrm{w}$ DIR TSE sequence $(\mathrm{TE}=83 \mathrm{~ms}$, $\mathrm{TR}=2 \mathrm{RR}$, fat suppression using spectral adiabatic inversion recovery (SPAIR) with in-plane resolution $1.25 \mathrm{~mm} \times 1.25 \mathrm{~mm}$, slice thickness $4 \mathrm{~mm}$ ). LGE MRI was also acquired with the same in-plane resolution with slice thickness $2.5 \mathrm{~mm}$. Both sequences were respiratory navigated, ECG gated with data acquisition during LA diastole.

\section{Results}

Diffuse left atrial wall enhancement is seen routinely using our T2w DIR TSE sequence immediately post ablation and reflects acute tissue edema (figures 1,2). Though the location of injury generally correlates with CARTO ablation points, the surrounding tissue is also clearly enhanced and suggests more diffuse LA wall injury (figure 3). LGE MRI, also performed immediately post ablation, shows a different pattern of LA wall enhancement (figure 4).

\section{Conclusion}

Delivery of RF energy during AF ablation to LA wall appears to cause changes not only in the regions where RF energy was directly applied, but also in the regions where no energy was delivered. If characteristics of LA wall (e.g. thickness, water content, conductivity) change during the procedure, this may have important implications for achieving permanent lesions leading to successful ablation. In addition, a different injury pattern is seen on LGE MRI in the acute setting. Further study of early ablation 

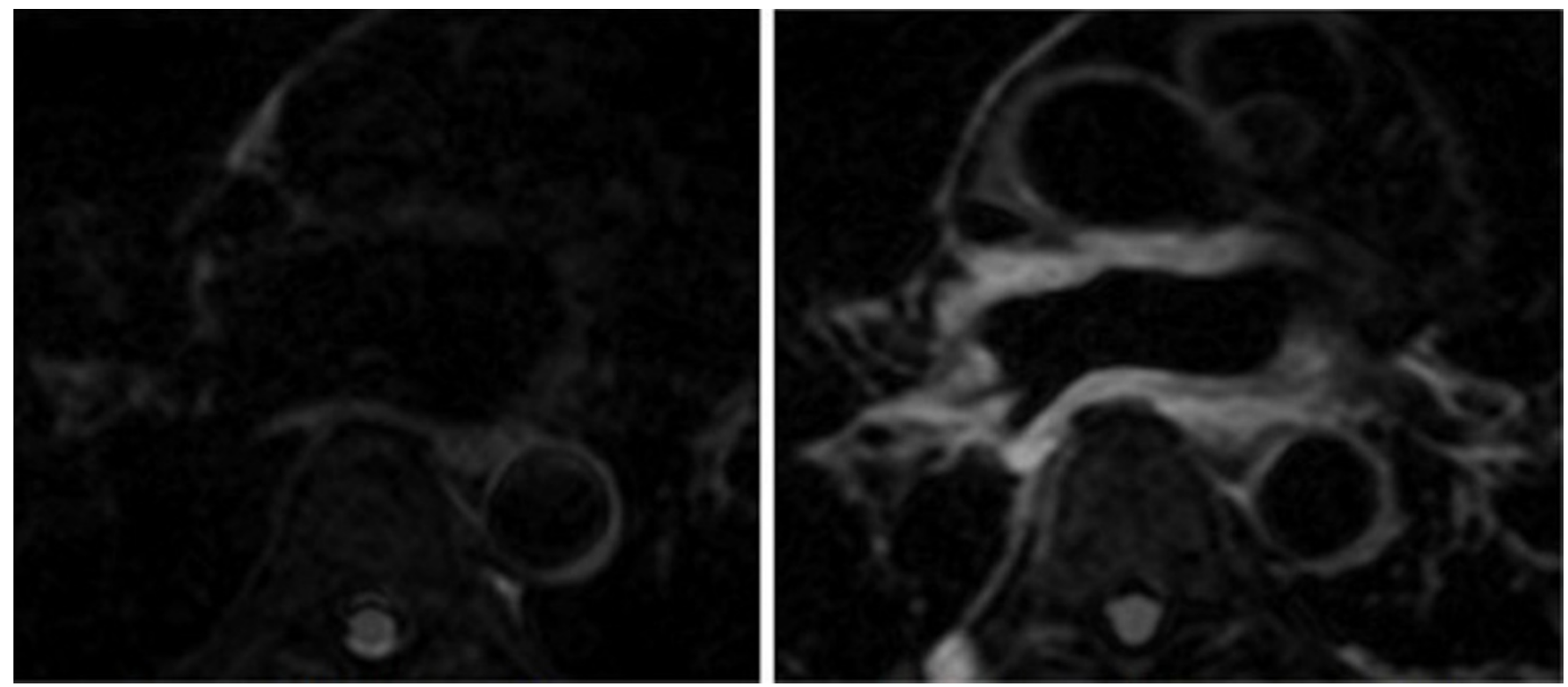

Figure I

a. T2w DIR FSE pre ablation (left) and post ablation (right). Left arterial wall is diffusely enhanced on this axial slice view on post ablation images.
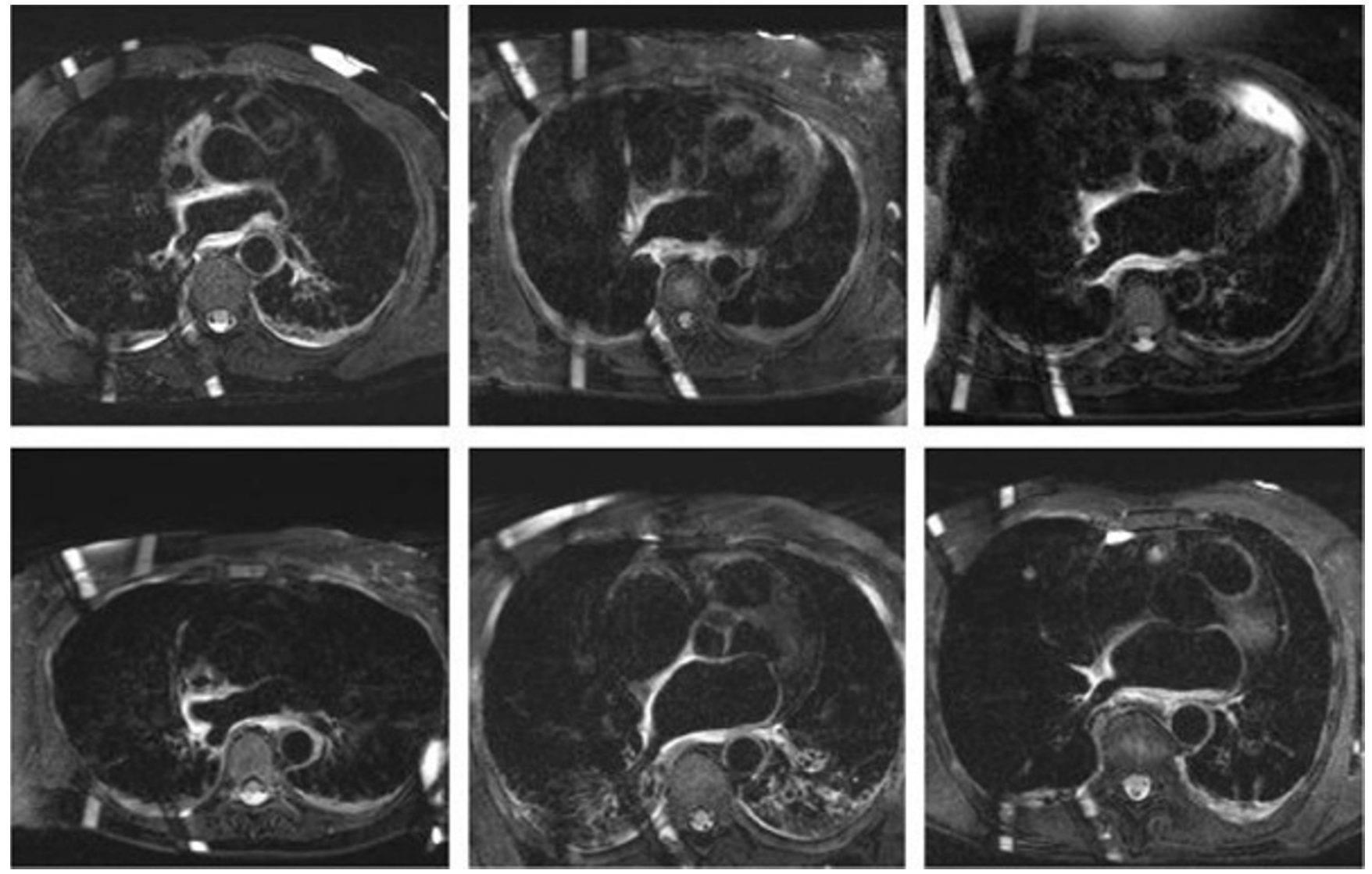

Figure 2

Examples of T2w DIR TSE immediately post ablation. 

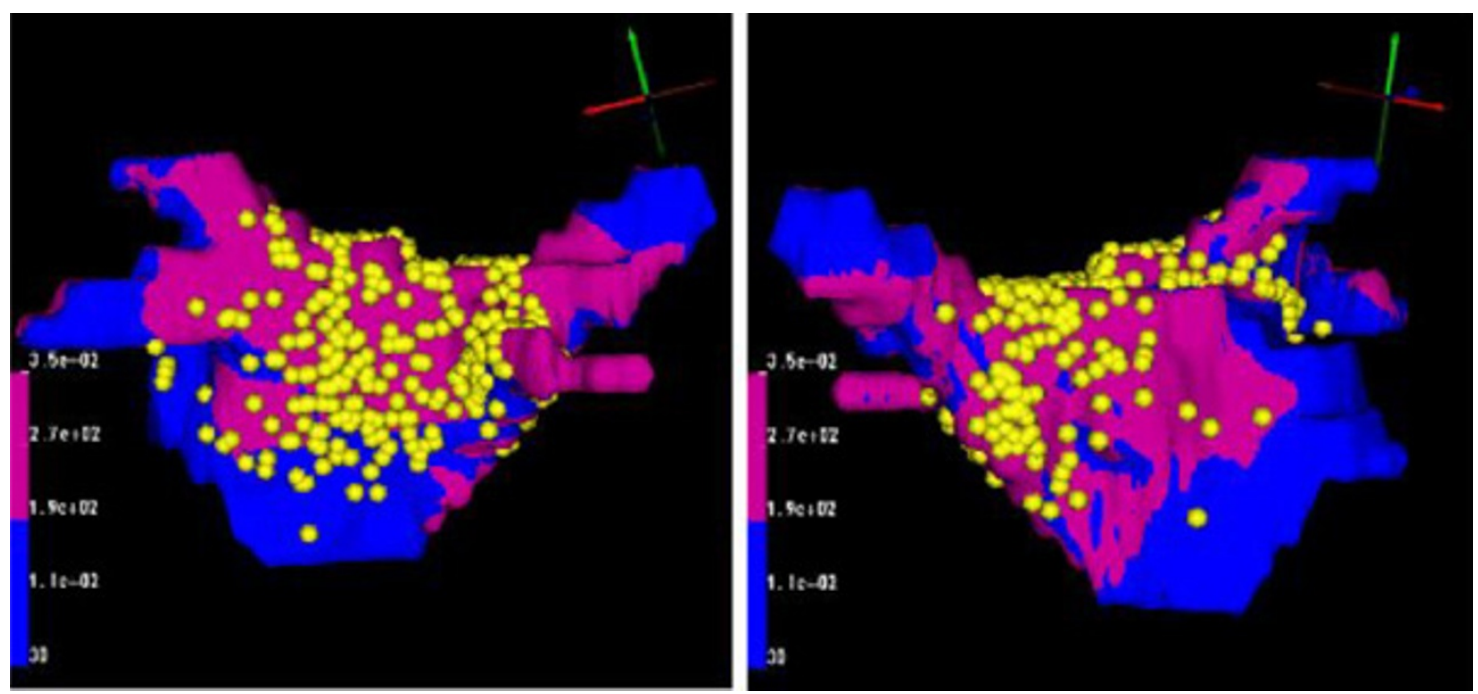

Figure 3

Projection of ablation points (yellow) onto surface mesh with T2w DIR TSE (purple).

LGE

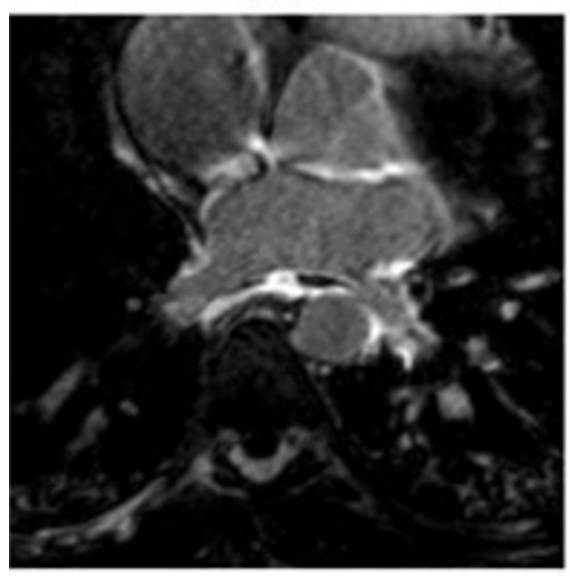

T2W DIR TSE

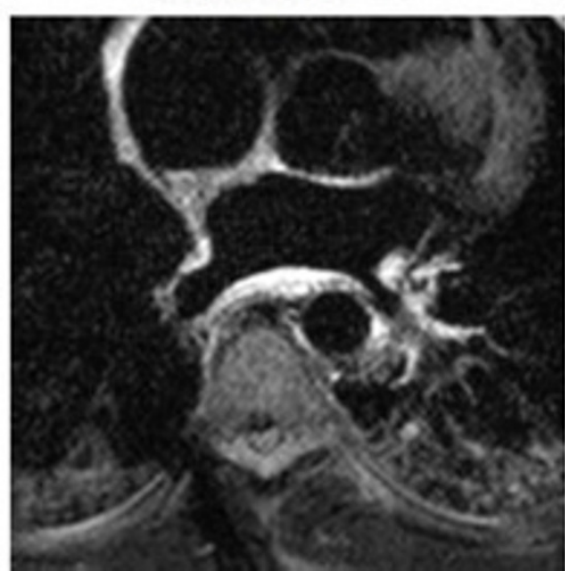

Fusion

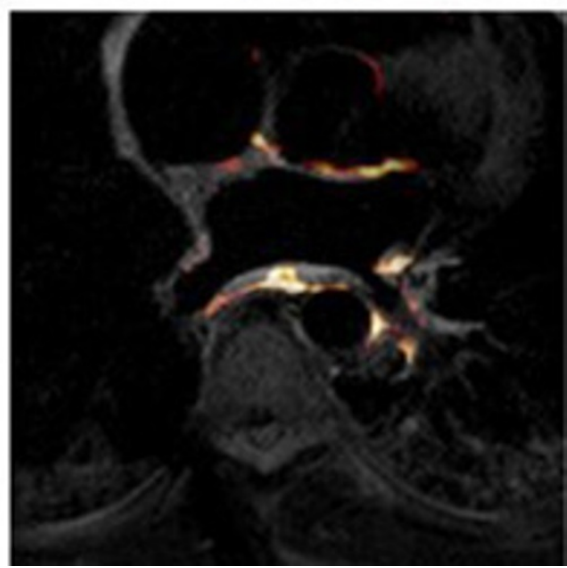

Figure 4

Fusion of LGE and T2w DIR TSE images. MR images acquired in EP-MRI lab on 3 T scanner immediately post AF ablation procedure.

injury on MRI may reduce the number of repeat procedures and improve outcomes.

\section{References}

I. Knowles, et al:: ISMRM 2009:487.

2. Peters, et al.: ISMRM 2009:4433.
Publish with Bio Med Central and every scientist can read your work free of charge

"BioMed Central will be the most significant development for disseminating the results of biomedical research in our lifetime. " Sir Paul Nurse, Cancer Research UK

Your research papers will be:

- available free of charge to the entire biomedical community

- peer reviewed and published immediately upon acceptance

- cited in PubMed and archived on PubMed Central

- yours - you keep the copyright
BioMedcentral 